\title{
Lipids and nutrition of the southern rock lobster, Jasus edwardsii, from hatch to puerulus
}

\author{
Charles F. Phleger ${ }^{\mathrm{A}}$, Matthew M. Nelson ${ }^{\mathrm{B}}$, Ben D. Mooney ${ }^{\mathrm{C}}$, Peter D. Nichols ${ }^{\mathrm{C}}$, Arthur J. \\ Ritar $^{\mathrm{D}}$, Greg G. Smith ${ }^{\mathrm{D}}$, Piers R. Hart ${ }^{\mathrm{D}}$, and Andrew G. Jeffs ${ }^{\mathrm{E}}$ \\ ${ }^{A}$ Department of Biology, San Diego State University, San Diego, CA 92182, USA; \\ phleger@sunstroke.sdsu.edu \\ ${ }^{B}$ Department of Zoology, University of Tasmania, Hobart, TAS 7001, Australia; \\ mmnelson@utas.edu.au \\ ${ }^{C}$ CSIRO Marine Research, Hobart, TAS 7001, Australia; Ben.Mooney@marine.csiro.au, \\ Peter.Nichols@marine.csiro.au \\ ${ }^{D}$ Tasmanian Aquaculture and Fisheries Institute, University of Tasmania, Taroona, TAS \\ 7053,Australia; Arthur.Ritar@utas.edu.au,Greg.Smith@dpiwe.gov.tas.au, \\ hart_piers@hotmail.com \\ ${ }^{E}$ NIWA-Auckland, 269 Khyber Pass Road, Newmarket, Box 109-695, Auckland, New \\ Zealand; a.jeffs@niwa.cri.nz \\ Corresponding author: Arthur.Ritar@utas.edu.au
}

\begin{abstract}
We examined the lipid class and fatty-acid composition of the southern rock lobster, Jasus edwardsii, phyllosomas larvae and puerulus stage to improve understanding of their nutrition in relation to aquaculture. Lipid is critical in the nutrition of larval crustaceans, including lobsters. Specimens were from Tasmanian waters, Australia, and North Island, New Zealand, waters. Analyses were by TLC-FID and capillary GC and GC-MS.

Phyllosomas larvae and nektonic pueruli were low in storage lipid (triacylglycerol), and phospholipid was the major lipid class. Sterol, mainly cholesterol, was the next most abundant class. The ratio of the essential omega- 3 fatty acid eicosapentaenoic acid (EPA) to the omega-6 fatty acid arachidonic acid (AA) was lower in newly hatched phyllosomas (1.21.3) than in other phyllosomas (stages III-XI; 2.8-6.7) and pueruli (3.8). Ratios of the omega-3 fatty acid DHA (docosahexaenoic acid) to EPA were also lower in newly hatched phyllosomas (0.5) than in later-stage phyllosomas (1.5-2.1) and pueruli (1.2). We have followed up these compositional data by successfully enriching the live diet (Artemia) of early phyllosomas with AA, EPA and DHA. This dietary manipulation has achieved ratios of these key polyunsaturated fatty acids similar to those of wild phyllosomas. These findings will be of significance to the future of rock-lobster aquaculture.
\end{abstract}

Keywords: phyllosoma, phospholipid, fatty acids, polyunsaturated fatty acids, EPA, DHA, AA, sterol, diacylglycerol

\section{Introduction}

The Australian rock-lobster fishery is an important natural resource making up $25 \%$ of the value of Australia's total fishery landings and presently worth around A $\$ 450$ million per annum. The fishery for southern rock lobster, Jasus edwardsii, is the second most valuable fishery in Tasmania, having a value of approximately A $\$ 40$ million (Punt and Kennedy 1997). 
This lobster species is also one of the most valuable fisheries in New Zealand, involving annual exports of over NZ\$100 million (Breen and Kendrick 1997). However, most rocklobster fisheries are fully exploited, so future expansion of output can only occur through aquaculture and enhancement programs.

The southern rock lobster goes through 11 planktonic larval stages lasting from 12 to 24 months before metamorphosis to the benthic puerulus stage (Lesser 1978; Phillips and Sastry1980; Booth 1994). Some progress has been made in rearing J. edwardsii larvae to puerulus, notably by Kittaka (1994a, $b$ ). More recently, Illingworth et al. (1997) obtained mean survival rates of over $60 \%$ to stage VII, but as very little is known about feeding in the wild, a need clearly remains for further nutritional research on this species. Larval nutrition is deemed a critical issue.

Lipids are very important in animal nutrition and, for crustaceans in particular, are critical for certain larval stages. There are, however, very few studies of lipids and fatty acids for any rock-lobster species. Essential fatty acids, such as eicosapentaenoic acid [EPA, 20:5 (n-3)] and docosahexaenoic acid [DHA, 22:6 (n-3)], cannot be produced de novo in most crustacean species in sufficient quantities to allow normal metabolic functioning, so they must be obtained from the diet (Kanazawa et al. 1979). The fatty-acid composition of newly hatched phyllosomas was found to be high in arachidonic acid [AA, 20:4 (n-6)], which may be correlated with maternal diet (Smith 1999), but to date no published studies have addressed the lipid class and fatty-acid composition of later-stage phyllosomas of J. edwardsii. Lipid is the primary energy-storage component of the puerulus of J. edwardsii and allows it to swim from the open ocean to shallow coastal waters (Jeffs et al. 1999). Phospholipid is the major lipid class of the puerulus and supplies energy for crossing the continental shelf of New Zealand (Jeffs et al. submitted). The two essential fatty acids EPA and DHA increased at the first-instar juvenile stage of J. edwardsii (Pearce 1997), and the increase may be correlated with commencement of feeding (Pearce 1997). Lipid class and fatty-acid profiles are available for commercially harvested adult J. edwardsii (Nichols et al. 1998b).

The major aim of our study, therefore, was to determine the signature lipid profiles of later-stage phyllosomas of J. edwardsii. These data are essential to providing a nutritionally balanced diet for susceptible larval stages in culture. A second aim was to assess the effect of preservation methods on lipid class and fatty-acid composition. We undertood this task to examine the feasibility of analysing preserved larval samples; if possible, analysis of the lipid composition of archived larval samples would enable aquaculturists to manipulate diets more effectively to provide the correct lipid composition to larvae. Enrichment studies using essential fatty acids such as EPA and DHA have been successfully carried out on the rotifer Brachionus plicatilis (e.g., by Nichols et al. 1989; Lewis et al. 1998). Enrichment studies with the brine shrimp Artemia salina have been conducted with omega-3 essential fatty acids to improve larval fish culture (Watanabe et al. 1982; Evjemo et al. 1997). Unless enriched, Artemia fail to provide a nutritionally balanced dietary food source with respect to essential fatty acids. Most techniques for newly hatched Artemia salina have been developed to suit the requirements of larval fish and prawns (Rees et al. 1994; McEvoy and Sargent 1998). Therefore our third aim was to manipulate the AA, EPA, and DHA composition of Artemia over a 5-day grow-out cycle to suit the requirements of southern rock lobster phyllosomas. 


\section{Materials and Methods}

\section{Rock lobster preservation experiment}

Two ovigerous females (approximately $600 \mathrm{~g}$ each), caught in coastal waters off southern Tasmania, were held for two months (September and October 1999) at TAFI Marine Research Laboratories, Hobart. Eggs hatched on 3 November 1999 and subsamples of pooled newly hatched phyllosomas (300-400 individuals, $0.3-0.4 \mathrm{~g}$ wet mass) were immediately preserved in $100 \%$ ethanol or $10 \%$ formalin in either glass or polypropylene jars. Pooled newly hatched phyllosomas were also either extracted fresh in chloroform/methanol/water, fresh frozen at $20^{\circ} \mathrm{C}$, or lyophilized.

\section{Wild rock lobster larvae-ethanol samples}

Existing phyllosoma and puerulus samples of Jasus edwardsii preserved in $100 \%$ ethanol were obtained from Russell Bradford at CSIRO Marine Laboratories. These samples included stage III-V and VII phyllosomas and nektonic pueruli and were mostly collected from RV Southern Surveyor between 12 February and 4 March 1998 at between $34^{\circ} 68^{\prime}-41^{\circ} 78^{\prime} \mathrm{S}$ and $133^{\circ} 36^{\prime}-144^{\circ} 45^{\prime} \mathrm{E}$ (off the west coast of Tasmania). One phyllosoma sample (stage V) was collected from RV Franklin during March 1997 between $43^{\circ} 68^{-}-44^{\circ} 15^{\prime} \mathrm{S}$ and $145^{\circ} 40^{\prime}-$ $146^{\circ} 84^{\prime}$ 'E. Six net systems were routinely used to collect these samples (Bruce et al. 1996). Samples were preserved in ethanol within 10-20 min of beign hauled aboard. Most samples were from surface tows (upper $2 \mathrm{~m}$ ) conducted during the night, and they were subsequently stored in the dark at room temperature.

\section{Wild New Zealand phyllosoma samples}

Wild Jasus edwardsii phyllosomas (stages V-IX, XI) were collected from RV Tangaroa by Engel net (fine-meshed midwater trawl) towed at a depth of $30 \mathrm{~m}$ at less than 2 knots for 1 h. The trawl was taken at $39^{\circ} 9.9^{\prime} \mathrm{S}, 178^{\circ} 41.4^{\prime} \mathrm{E}(2250-2360 \mathrm{~m}) 56 \mathrm{~km}$ off the coast of the North Island, New Zealand, on 12 April 2000 at night (2200-2300). All phyllosomas were sorted from the rest of the catch upon net landing and transferred into liquid nitrogen while alive. The frozen samples were shipped to CSIRO Marine Laboratories and analyzed immediately. Fresh masses were $0.2718 \mathrm{~g}$ for stage XI phyllosomas ( 1 only), $0.0877 \mathrm{~g}$ for stage IX ( 1 only), $0.04982 \mathrm{~g}$ for stage VIII ( 5 individuals pooled), $0.3473 \mathrm{~g}$ for stage VII (5 pooled), $0.2127 \mathrm{~g}$ for stage VI (5 pooled), and $0.2227 \mathrm{~g}$ for stage $\mathrm{V}$ ( 5 pooled). For comparative purposes, $10 \mathrm{~L}$ of seawater collected by CTD $3 \mathrm{~m}$ below the surface was filtered for phytoplankton and other particulate matter at the area where the New Zealand phyllosomas were collected.

\section{Feeding experiment-Artemia enrichment}

Artemia cysts (INVE, Great Salt Lake Prime Gold) were decapsulated and hatched at 28 $\pm 1^{\circ} \mathrm{C}$ in 50 -L white fibreglass cones in filtered brackish water $(0.2 \mu \mathrm{m}, 27 \pm 1 \%)$. After 24 h, newly hatched Artemia nauplii were removed from the hatching cones, rinsed in fresh water for $2 \mathrm{~min}$, and transferred to 1000 -L conical tanks at a density of 4 animals $\mathrm{ml}^{-1}$ in filtered seawater $\left(0.2 \mu \mathrm{m}, 34 \pm 1 \%, 27 \pm 1^{\circ} \mathrm{C}\right)$. Artemia were fed twice daily with an oatbran-based diet consisting of oat bran, wheat germ, and lecithin (50:6:4 by weight).

After 4 days, Artemia were harvested, rinsed, suspended (10,000 Artemia) in 1-L beakers containing seawater and fed one of three enrichment diets (see below) for $24 \mathrm{~h}$. Triplicate 
samples (10,000 Artemia) for each enrichment were rinsed and stored for analysis. The three enrichment diets were added to beakers at a rate of $0.6 \mathrm{~g} \mathrm{~L}^{-1}$ and consisted (by weight) of (1) Tetraselmis suecica, cultured in batches, cell density measured daily; (2) oat bran, wheat germ, and lecithin (50:6:4), plus MaxEPA and A1 ARASCO (arachidonic acid single cell oil) (40\% in 4.5:1 ratio; Martek Biosgenes, USA) (for convenience, we have termed this diet oats/EPA/AA); and (3) A1 DHA-Selco (INVE Group, Belgium).

The diets were prepared daily; each was blended finely in $500 \mathrm{ml}$ of fresh water, passed through a $63-\mu \mathrm{m}$ screen, and transferred to the beakers. The fibrous nature of oats prevented all of the diet from passing through the screen, so the remaining portion was dried and weighed for calculation of the daily amount fed. The performance of each diet was assessed in terms of survival, growth, and fatty-acid and lipid profiles of Artemia.

\section{Sample preparation}

Artemia and feed samples were filtered through 4.7-cm Whatman glass filters (GF/F) and rinsed with $0.5 \mathrm{M}$ ammonium formate. They were lyophilized overnight before analysis. Dry masses of the samples ranged from 56 to $263 \mathrm{mg}$, and masses of lipid were $0.8-49.7 \mathrm{mg}$.

\section{Lipid extraction and analysis}

Samples were quantitatively extracted with a modified Bligh and Dyer (1959) one-phase methanol:chloroform:water extraction (2:1:0.8, by vol); the samples were extracted overnight, and the phases were separated the following day by the addition of chloroform and water (final solvent ratio, 1:1:0.9, by vol, methanol:chloroform:water). The total lipid was concentrated (i.e., solvents were removed in vacuo) by rotary evaporation at $40^{\circ} \mathrm{C}$. Lipidclass analyses were conducted immediately; samples were stored for no more than 3 days in a known volume of chloroform.

We analyzed an aliquot of the total lipid using an Iatroscan MK V TH10 thin-layer chromatography-flame-ionization detector (TLC-FID) analyzer (Tokyo, Japan) to determine the abundance of individual lipid classes (Volkman and Nichols 1991). Samples were applied in duplicate or triplicate to silica-gel SIII Chromarods (5- $\mu$ m particle size) with $1-\mu 1$ disposable micropipettes. Chromarods were developed in a glass tank lined with preextracted filter paper. The solvent system used for the lipid separation was hexane:diethyl ether:acetic acid (60:17:0.2, by volume), a mobile phase resolving nonpolar compounds such as wax esters (WE), triacylglycerols (TAG), free fatty acids (FFA), and sterols (ST). A second nonpolar solvent system of hexane/diethyl ether ( $96: 4$ by volume) was also used for selected samples to separate hydrocarbon from WE and TAG from diacylglyceryl ether (DAGE). After development, the chromarods were oven-dried and analysed immediately to minimize adsorption of atmospheric contaminants. The FID was calibrated for each compound class (phosphatidylcholine, cholesterol, cholesteryl ester, oleic acid, squalene, WE [derived from fish oil], TAG [derived from fish oil], and DAGE [purified from shark liver oil]; 0.1-10 $\mu \mathrm{g}$ range). Peaks were quantified on an IBM-compatible computer with DAPA software (Kalamunda, Western Australia). Iatroscan results are generally reproducible to $\pm 5-10 \%$ for individual lipid classes (Volkman and Nichols 1991; Nichols et al. 1998a).

An aliquot of the total lipid was treated with methanol:hydrochloric acid:chloroform (10:1:1, by volume; $80^{\circ} \mathrm{C}, 2 \mathrm{~h}$ ). The fatty-acid methyl esters (FAME) products were extracted into hexane:chloroform $(4: 1$, by volume, $3 \times 1.5 \mathrm{ml})$ and the FAME mixture was 
treated with N,O-bis-(trimethylsilyl)-trifluoroacetamide (BSTFA, $50 \mu \mathrm{l}, 60^{\circ} \mathrm{C}, 1 \mathrm{~h}$ ) to convert sterols to their corresponding TMSi (trimethylsilyl) ethers.

Gas chromatographic (GC) analyses of methyl esters of fatty acids were performed with a Hewlett Packard 5890A GC (Avondale, PA, USA) equipped with an HP-1 cross-linked methyl silicone fused-silica capillary column ( $50 \mathrm{~m} \times 0.32 \mathrm{~mm}$ i.d.), an FID, a split/splitless injector, and an HP 7673A auto sampler. Hydrogen was the carrier gas. After addition of methyl nonadecanoate and methyl tricosanoate internal standards, samples were injected in splitless mode at an oven temperature of $50^{\circ} \mathrm{C}$. After $1 \mathrm{~min}$, the oven temperature was raised to $150^{\circ} \mathrm{C}$ at $30^{\circ} \mathrm{C} \mathrm{min}^{-1}$, then to $250^{\circ} \mathrm{C}$ at $2^{\circ} \mathrm{C} \mathrm{min}^{-1}$, and finally to $300^{\circ} \mathrm{C}$ at $5^{\circ} \mathrm{C} \mathrm{min}$. Peaks were quantified with Waters Millennium software (Milford, MA, USA). Individual components were identified from mass spectral data and by comparison of retention-time data with those obtained for authentic and laboratory standards. GC results are subject to an error of $\pm 5 \%$ of individual component abundance. GC-mass spectrometric (GC-MS) analyses were performed on a Finnigan Thermoquest GCQ GC-mass spectrometer (Austin, TX, USA) fitted with an on-column injector. The GC was fitted with a capillary column similar to that described above.

\section{Results}

Lipid classes-newly hatched phyllosomas (preservation experiment) and adults

Phospholipid (PL) was the major lipid class in newly hatched phyllosomas and adults (Table 1). Lowest PL values occurred in formalin-preserved newly hatched phyllosomas. FFA were also somewhat higher in formalin-preserved newly hatched phyllosomas than in other samples. ST (mainly cholesterol) was the second most abundant lipid class. Minor levels of WE and very low levels of TAG were only present in newly hatched phyllosomas (Table 1). Minor levels of diacyglycerols (DG) were detected in newly hatched phyllosomas. Lipid was $43.5-56.5 \mathrm{mg} \mathrm{g}^{-1}$ dry mass in newly hatched phyllosomas and $31.0 \mathrm{mg} \mathrm{g}^{-1}$ dry mass in adults.

\section{Lipid classes-wild later-stage phyllosomas}

PL was the major lipid class in all J. edwardsii phyllosomas from both Tasmanian and New Zealand ocean waters (Table 1). DG was the second most abundant in all New Zealand phyllosomas but was only second in one Tasmanian phyllosoma sample (stage V) and equal to ST in stage VI Tasmanian phyllosomas. ST was the third major lipid class in New Zealand phyllosomas and was second in abundance in most Tasmanian phyllosomas. Cholesterol was the major sterol present. New Zealand phyllosomas also had very low TAG and FFA, but neither these lipid classes nor WE was detected in Tasmanian phyllosomas (Table 1). Lipid levels were 95-347 $\mathrm{mg} \mathrm{g}^{-1}$ dry mass in Tasmanian phyllosomas and 186-344 $\mathrm{mg} \mathrm{g}^{-1}$ in New Zealand phyllosomas.

When calculated as milligrams per phyllosoma, total lipid increased markedly at stages IX-XI for New Zealand phyllosomas (55.9-68.8 mg lipid per animal) compared to stages VVIII (7.4-9.7 mg lipid per animal). PL was the major lipid class (71.9-80.6\% of total lipid) in filtered phytoplankton and other particulate matter collected at the area where the New Zealand phyllosomas were collected; TAG was second (8.9-17.6\%) and WE third in percent composition (6.4-12.3\%). Lipid content of these particulate-matter samples was very low $\left(0.01-0.02 \mathrm{mg} \mathrm{L}^{-1}\right)$. 


\section{Lipid classes—wild pueruli}

Nektonic J. edwardsii pueruli from Tasmanian waters were dominated by PL and had low DG and ST (Table 1). Lipid levels were quite low compared to those of phyllosomas, $34.8 \mathrm{mg} \mathrm{g}^{-1}$ of dry mass. No WE, TAG, or FFA was detected.

\section{Fatty acids—newly hatched phyllosomas (preservation experiment) and adults}

The main fatty acids in all newly hatched phyllosomas were 16:0, 18:1(n-9)c, AA, EPA, and DHA (Table 2). AA comprised 11.6-11.9\% (of total FA). Formalin-preserved newly hatched phyllosomas and adult J. edwardsii had less AA. AA values for the newly hatched phyllosomas were considerably higher than those for all other phyllosoma samples and higher than those for the puerulus (Table 2, Fig. 1). EPA values were also higher for newly hatched phyllosomas (frozen, lyophilized, and ethanol-preserved) and adults; formalin-preserved newly hatched phyllosomas showed lower values. EPA values were higher for newly hatched than for later-stage phyllosomas samples and nektonic pueruli. The EPA/AA ratios were thus lowest in newly hatched phyllosomas (1.2-1.3), higher in adults (2.5), and highest in laterstage phyllosomas (2.8-6.7) and pueruli (3.8).

DHA values were higher in adult southern rock lobsters ( $16.6 \%$ of total FA) than in newly hatched phyllosomas (less in formalin-preserved specimens, Table 2). Later-stage phyllosomas had higher DHA than newly hatched phyllosomas. Nektonic pueruli also had higher DHA (Table 2, Fig. 1). These differences are reflected in DHA/EPA ratios for adults (0.9), newly hatched phyllosomas (0.5), later-stage phyllosomas (1.5-2.1) and pueruli (1.2). Newly hatched phyllosomas had more DPA [docosapentaenoic acid, 22:5 (n-3)] than adult lobsters, later-stage phyllosomas, and pueruli (Table 2). The total polyunsaturated fatty acids (PUFA) for adults and newly hatched phyllosomas was also greater than for later-stage phyllosomas and pueruli.

The total monounsaturated fatty acids (MUFA) was also lower for adults and newly hatched phyllosomas. Oleic acid [OA, 18:1(n-9)c] values for adults and newly hatched phyllosomas were lower than those for other samples (Table 2). Vaccenic acid [18:1(n-7)c] levels were slightly higher for newly hatched phyllosomas than for other samples. There were lower levels of 20:1(n-11)c fatty acid in newly hatched phyllosomas than in later-stage phyllosomas and pueruli (Table 2). This fatty acid was not detected in adults.

The PUFA 18:4(n-3) was not detected in adults, newly hatched phyllosomas, or pueruli but was present at low levels in later-stage phyllosomas (Table 2). Branched fatty acids were present at less than $1 \%$ in all specimens and all stages. The major saturated fatty acid (SFA) in all specimens was palmitic acid (16:0); less was detected in adults and newly hatched phyllosomas (more for formalin-preserved samples) than in other samples (Table 2). This difference is reflected in the total SFA for adults and newly hatched phyllosomas (more for formalin-preserved specimens); less was detected than in later-stage phyllosomas and pueruli.

\section{Fatty acids-wild later-stage phyllosomas}

values of AA were lower in later-stage phyllosomas than in newly hatched phyllosomas, and some locations differed slightly. Tasmanian phyllosomas had less AA than New Zealand phyllosomas (Table 2, Fig. 1). Some between-location differences in EPA, which was lower in later-stage phyllosomas than in newly hatched phyllosomas, wers also evident. Tasmanian phyllosomas had less EPA than New Zealand phyllosomas. More DHA was detected in laterstage phyllosomas than in newly hatched phyllosomas, and less on average was found in 
Tasmanian phyllosomas. The PUFA 18:4(n-3) was lower in Tasmanian phyllosomas, and 18:4(n-3) also decreased slightly with increasing stage in New Zealand phyllosomas (Table 2). OA was higher in Tasmanian phyllosomas. It generally increased with increasing phyllosoma stage in New Zealand phyllosomas. The MUFA 20:1(n-11)c was also present at higher levels in later stages of the New Zealand phyllosomas.

The fatty-acid composition of three particulate-matter samples from the New Zealand waters where the phyllosomas were collected showed $0.3 \% \mathrm{AA}, 1.6-2.9 \% \mathrm{EPA}$, and $4.9-$ $7.7 \%$ DHA (ratios of EPA to AA, 5.4-10.9; DHA to EPA, 2-3.5). The sum (n-3) was 10$15 \%(\%$ of total FA) and the sum (n-6) was $4.3-4.8 \%$ [ratio (n-3)/(n-6) 2.2-3.5]. The sum SFA was 40-46\%, the sum MUFA 28-33.6\%, and the sum PUFA $14.9-19.3 \%$.

Feeding experiment-lipid classes of feeds and Artemia

The algal feed contained mostly PL (Table 3). Oats/EPA/AA and DHA Selco feeds contained primarily TAG, with less PL and much less ST, FFA and WE. Lipid contents of the feeds only were $109 \mathrm{mg} \mathrm{g}^{-1}$ (algae, T. suecica), $288 \mathrm{mg} \mathrm{g}^{-1}$ (oats/EPA/AA) and $806 \mathrm{mg} \mathrm{g}^{-}$ ${ }^{1}$ (mg g ${ }^{-1}$ dry mass) (DHA Selco). For Artemia fed these diets, lipid was $98 \mathrm{mg} \mathrm{g}^{-1}$ dry mass on the algal diet, $259 \mathrm{mg} \mathrm{g}^{-1}$ on the oats/EPA/AA diet, and $297 \mathrm{mg} \mathrm{g}^{-1}$ on the DHA Selco diet. Artemia fed the algal diet had primarily PL with less ST, FFA, TAG and WE (Table 3). Artemia fed either of the lipid-rich diets were high in TAG with PL second in abundance.

\section{Artemia feeds-fatty-acid composition}

The algal feed had as the major PUFA 18:2(n-6), 18:4(n-3), EPA, and $\mathrm{C}_{16}$ PUFA (Table 4). DHA was low in the algal feed, reflected in the very low DHA/EPA ratio (0.04). The EPA/AA ratio was 3.3. These PUFA were reflected in a high total PUFA, but because the PUFA were dominated by 18:2 (n-6) there was a relatively low $n-3 / n-6$ ratio $(0.64)$. The principal SFA included 16:0 and 18:0 (Table 4).

The oats/EPA/AA feed was enriched in AA and EPA and contained less DHA (Table 4). The major MUFA were 18:1(n-9)c and 16:1 (n-7)c. The EPA/AA ratio was 1.3, the ratio (n3)/(n-6) 1.1, and the ratio DHA/EPA 0.64. Palmitic acid, 16:0, was the major SFA; 14:0 and 18:0 were relatively lower. The DHA Selco feed was characterised by greater DHA with relatively less AA and EPA (Table 4). The DHA/EPA ratio was 3.9, and the EPA/AA ratio 3.2. This diet was characterised by low (n-6) fatty acids and the sum of the (n-6) fatty acids was less than the sum of the (n-3) fatty acids. The MUFA included primarily 18:1(n-9)c, 16:1 $(n-7) c$, and 18:1 (n-7)c. Palmitic acid (16:0) was the major SFA; 14:0 and 18:0 were lower.

\section{Artemia fatty-acid composition}

Artemia fed the algal diet had low AA, EPA. and DHA (Table 4, Fig. 2). The principal fatty acids in Artemia fed algae included 18:1(n-9)c, 18:1(n-7)c, 18:2(n-6), 16:0, and 18:0. MUFA were a greater percentage than total PUFA. The sum (n-3) was less than the sum (n6). The EPA/AA ratio was 1.9, the DHA/EPA ratio only 0.04 .

Artemia fed the oats/EPA/AA diet had high AA and EPA and less DHA (Table 4, Fig. 2). This pattern was reflected in the sum PUFA, an EPA/AA ratio of 1.3, and a DHA/EPA ratio of 0.47. Levels of 18:1(n-9)c were greater than those of 18:1 (n-7)c, and 16:1 (n-7)c. The major SFA included 16:0, 18:0, and 14.0.

Artemia fed the DHA Selco diet had low AA and high DHA relative to those fed the other enrichment diet (Table 4, Fig. 2). EPA was $8.7 \%$ of total FA. The low AA was reflected in a higher EPA/AA ratio of 3.2, and the high DHA in a high DHA/EPA ratio (1.8). 
The sum PUFA was similar to the sum PUFA for the Artemia fed the oat/EPA/AA diet, but the sum (n-3) was higher. MUFA compositions were similar in the two enrichment diets; the sum MUFA was almost identical. The sum SFA was also identical for the two enrichment diets, as was the SFA composition.

\section{Discussion}

Lipid classes and fatty acids—southern rock lobster (preservation experiment)

Formalin-preserved samples of newly hatched phyllosomas differed significantly in fattyacid composition from samples stored otherwise (in particular, they had lower AA, EPA, and DHA, Table 2). PUFA profiles of these formalin-treated samples were seriously compromised, so formalin should not be used for samples to be analyzed for lipid and fattyacid composition. In contrast, the ethanol-preserved newly hatched phyllosoma samples did not differ in fatty-acid profile from fresh extracted, frozen, or lyophilized ones (Table 2). We were therefore able to use ethanol-stored phyllosomas (from Tasmanian waters) in our study. Because ethanol extracts lipid, the sample plus all ethanol must be used in the Bligh-Dyer extraction. The extraction is therefore performed with chloroform, ethanol, and water, where ethanol replaces methanol. Not only were the fatty-acid profiles of ethanol-preserved samples nearly identical to those of fresh, frozen, and lyophilized samples (Table 2), the level of FFA in the lipid-class profile was also very low (Table 1). High FFA levels would indicate lipid degradation. In the case of historical ethanol-preserved samples, in which the ethanol preservative may have been exchanged, some of the lipid may be missing, so care is needed in selecting preserved samples for lipid analysis.

\section{Lipid classes-wild southern rock lobster}

PL was the major lipid class in the southern rock lobster (adult, newly hatched phyllosomas, phyllosomas from New Zealand and Tasmania, and pueruli from Tasmania) and comprised $82.5-95.9 \%$ (of total lipid) in all samples. Our lipid-class data for the newly hatched phyllosomas are in general agreement with those of Smith (1999) in that PL is the major lipid class. Smith (1999) noted low levels of hydrocarbon (3-6\%), no DG, low TAG (2.1-2.7\%), and somewhat higher sterol (8.7-10.9\%) in newly hatched phyllosomas of $J$. edwardsii. Some of these differences may be due to small variations in methods. Pearce (1997) found PL to be the major lipid class in pueruli of J. edwardsii, which also had low levels of DG and TAG. TAG increased in relative percent in the settled pueruli, perhaps in preparation for the moult (Pearce 1997). DG was the second most abundant lipid class in most of these larval rock lobsters (stage V-XI and nektonic pueruli); ST ( $>95 \%$ cholesterol) was usually third in abundance.

PL (mostly phospholipid) and ST primarily function as membrane structural lipids (Pond and Sargent 1998), but in certain organisms, such as the Antarctic krill Euphausia superba, PL are depleted as energy reserves, in addition to depletion of TAG (Virtue et al. 1993; Hagen et al. 1996). Interestingly, PL is also depleted in J. edwardsii pueruli (Pearce 1997; Jeffs et al. submitted), in keeping with the role of lipid as the primary energy store of nektonic pueruli of J. edwardsii (Jeffs et al. 1999). DG also may play a less significant secondary role as energy reserve in J. edwardsii pueruli (Jeffs et al. submitted). Both PL and DG may play a similar role in later-stage phyllosomas (Table 1), because almost no TAG or WE were detected in them. TAG, a short-term energy-reserve molecule, is generally the most common lipid reserve in marine organisms, whereas WE a long-term energy-reserve molecule, is less 
common (Benson and Lee 1975). The occurrence of PL as the major lipid class in $J$. edwardsii phyllosomas and nektonic pueruli could be due to its transparency in vivo, which could provide protection to the phyllosomas from predation in the water column, as proposed for puerulus by Jeffs et al. (submitted).

Cholesterol is necessary for the normal growth and survival of juvenile American lobsters, Homarus americanus (D'Abramo et al. 1984). Cholesterol biosynthesis does not occur from $\left[{ }^{14} \mathrm{C}\right]$-labeled precursors in spiny lobsters (Teshima and Kanazawa 1971). Replacement of cholesterol with phytosterols (mostly $\beta$-sitosterol) did not result in satisfactory growth and survival of H. americanus (D'Abramo et al. 1984). In our study (Table 1), ST ( $>95 \%$ cholesterol ) levels are higher in adults and newly hatched and early stage phyllosomas $(6.2-12.0 \%)$ than in later stages (stages $\mathrm{V}-\mathrm{XI})(0.8-5.5 \%)$ and nektonic pueruli (4.1\%). The reason(s) for this difference remain(s) to be determined.

Although lipid is relatively low in adults and newly hatched phyllosomas (31.0-56.5 mg $\mathrm{g}^{-1}$ lipid, as dry mass), it is substantially greater in later-stage phyllosomas (94.6-347.3 $\mathrm{mg} \mathrm{g}^{-}$ ${ }^{1}$ lipid) (Table 1). Lipid levels increased in later-stage phyllosomas (New Zealand) from $185.7-242.1 \mathrm{mg} \mathrm{g}^{-1}$ (stage V-VIII) to $279.4-344.0 \mathrm{mg} \mathrm{g}^{-1}$ in stage IX-XI. Total lipid in nektonic pueruli $\left(34.8 \mathrm{mg} \mathrm{g}^{-1}\right.$ ) was low in comparison. This large decrease in lipid isin keeping with evidence that pueruli do not feedi (Kittaka 1990). Fat bodies decrease in size as lobsters develop from the transparent to the pigmented puerulus stage (Takahashi et al. 1994). According to Lemmens (1994), in Panulirus cygnus, energy reserves are accumulated during the last phyllosoma stage and are used during the nonfeeding puerulus stage.

\section{Fatty acids—wild southern rock lobster}

One of the most obvious characteristics of the fatty-acid profile of newly hatched phyllosomas is their high AA levels (11.6-11.9\% of total FA, not including the formalinpreserved specimens) relative to later-stage phyllosomas (1.4-3.1\%) (Table 2). Smith (1999) first noted elevated levels of AA in newly hatched stage I phyllosomas of J. edwardsii (6.8$9.3 \%$ of total FA). It was pointed out that AA is an essential fatty acid usually only found in small quantities in marine organisms (Olsen 1998). Smith (1999) suggested that the maternal diet source before spawning influences the fatty-acid composition of the total lipid fraction of newly hatched phyllosomas. Adult J. edwardsii contain 7.3\% AA (Table 2; Nichols et al. $1998 \mathrm{~b}$ ). The similarity of the fatty-acid profiles of adult and newly hatched J. edwardsii phyllosomas confirms this suggestion. AA may also play a specific role in crustacean nutrition, because consistent levels are usually present at the earliest stages of larval development (Chapelle 1986).

Newly hatched and later-stage phyllosomas also differ in other notable ways, namely the higher EPA and lower DHA at the later stages (Table 2). These fatty acids are both considered essential because they are not synthesized by the animal from acetate- $\left[{ }^{14} \mathrm{C}\right]$, as has been demonstrated in European lobster (Zandee 1967). Both $\left[{ }^{14} \mathrm{C}\right] \mathrm{EPA}$ and $\left[{ }^{14} \mathrm{C}\right] \mathrm{DHA}$ were incorporated at high levels in adult Panulirus japonicus into phospholipids such as phosphatidylcholine and phosphatidylinositol (Kanazawa and Koshio 1994). EPA and DHA must be synthesized from fatty-acid precursors or be obtained from the diet. In the case of newly hatched phyllosomas, they are derived from the adult broodstock. Marine oils (cod liver oil) that contain these essential PUFA have been demonstrated to be superior to vegetable oils (corn oil or hydrogenated coconut oil, devoid of EPA and DHA) in the diet of Homarus americanus (Castell and Covey 1976). 
EPA is typically found in higher proportion in diatoms, whereas dinoflagellates and other flagellates contain more DHA than EPA. Diatoms are characterised by high EPA and high 16:1/16:0 ratio as noted in a recent food-chain study (Nelson et al. 2000). Although both Tasmanian and New Zealand phyllosomas show a higher EPA-to-AA ratio than do newly hatched phyllosomas, the 16:1/16:0 ratio is low. The higher DHA-to-EPA ratios in the laterstage phyllosomas than in early stages (Table 2 ) probably derive from feeding in the pelagic plankton environment and may reflect input from dinoflagellates or other plankton rich in DHA.

The $\mathrm{C}_{18}$ omega-3 PUFA 18:4(n-3) was only detected in the later-stage phyllosomas (Table 2). This PUFA is a major fatty acid in the prymnesiophyte Isochrysis sp. (T-ISO) and in the cryptomonad Chroomonas salina (Volkman et al. 1989). It may be passing though the food chain to later-stage phyllosomas.

High levels of OA in later-stage phyllosomas indicate a zooplankton-rich diet. Herbivorous salps (Salpa thompsoni, Urochordata), for example, have only 3-7\% oleic acid (Phleger et al. 2000), as a result of their phytoplankton-rich diet. The transparent phyllosomas may feed on transparent gelatinous organisms in the open ocean (D. Ritz and T Koslow, personal communication). Signature lipid profiles such as those of OA (Table 2) for later-stage $J$. edwardsii phyllosomas are more closely correlated with those of cnidarian jellies than with those of salps (Nelson et al. 2000; unpublished data). For example, high OA (18.626.4\%) levels are characteristic of certain cnidarian jellies, such as Calycopsis borchgrevinki and Stygiomedusa gigantea (Nelson et al. 2000), but the EPA-to-DHA ratios do not match. More signature lipid profiles are needed for gelatinous zooplankton collected from waters near where the phyllosomas are located. In addition, our data provide evidence $(<1 \%$ branched-chain, odd-numbered fatty acids; Table 2 footnote) that bacteria are not a significant component in the phyllosoma diet.

Our fatty-acid data for AA, EPA, and DHA of J. edwardsii puerulus (Table 2) are in agreement with those of Pearce (1997). Marked increases in AA, EPA, and DHA were reported in the early-instar juveniles (Pearce 1997), and these increases were attributed to diet. PUFA deficiency can be an important problem in aquaculture operations, resulting in early mortality and various ailments.

\section{Feeding experiment-Artemia enrichments}

The oats/EPA/AA diet more successfully enriched Artemia, after $24 \mathrm{~h}$, in AA (from 3.4\% to $8.9 \%$ of total FA) and EPA (from $6.3 \%$ to $11.3 \%$ ) than did the Tetraselmis diet (Table 4). It increased TAG levels to $71 \%$ of total lipid; the algal diet yielded only $4.3 \%$ (Table 3 ). This diet program has excellent potential for providing EPA- and AA-enriched Artemia to newly hatched phyllosomas, which contain elevated levels of these two PUFA (11\% AA, 15\% EPA; Table 2, Fig. 2).

During later-stage phyllosoma development (stages IV to XI, Table 2), a shift in the ratios of the essential PUFA occurs; both the EPA-to-AA and the DHA-to-EPA ratios increase, suggesting a decrease in the requirement for AA while DHA assumes greater importance.

A number of studies have demonstrated enrichment of Artemia with essential omega-3 fatty acids (in particular DHA), primarily to improve fish larval culture. Newly hatched Artemia nauplii took up omega-3 highly unsaturated fatty acids (HUFA) homogenised with raw egg yolk, water, and bakers yeast and improved the growth of fish (Watanabe et al. 1982) that fed on them. Increased survival and biomass of the larval sea bass Dicentrarchus labrax 
were attributed to the omega-3 HUFA content of enriched Artemia nauplii in their diet (Van Ballaer et al. 1985). Artemia enrichment was reviewed by Leger et al. (1987), and the importance of DHA enrichment was stressed, because DHA is usually absent from Artemia nauplii. Phospholipid was reported to be the most efficient lipid class for delivery of DHA to Artemia nauplii (Harel et al. 1999). Feeding experiments with J. edwardsii phyllosoma larvae have used Artemia as feed for the first two stages and then mussels, Mytilus edulis, for the later stages (Kittaka 1994). Artemia (2-3 mm) reared on microalgae were found to be suitable food for stage I to VI J.edwardsii phyllosoma larvae (Tong et al. 1997).

The DHA Selco diet successfully enriched Artemia after $24 \mathrm{~h}$ to $15.4 \%$ DHA (of total FA), compared to $0.2 \%$ for the algal diet and 5.2\% for the oats/EPA/AA diet (Table 4, Fig. 2). The DHA-to-EPA ratios were increased to 2.2 in Artemia fed DHA Selco from 0.03 and 0.52 in Artemia fed oats/EPA/AA (Table 4).

The lipid and fatty-acid data presented in this report confirm the possibility of designing relatively simple and low-cost Artemia diets with PUFA profiles that may offer potential for use with rock-lobster larvae. The PUFA profiles of later-stage phyllosomas of rock lobster, obtained here for the first time, change markedly during development. High levels of the essential PUFA were obtained with Artemia fed simple diet mixes based on off-the-shelf products. Also, for the first time Artemia were simultaneously enriched with all three essential PUFA, EPA, DHA, and in particular AA. These enrichment results for DHA, EPA, and AA in Artemia should be of potential use for aquaculture, more specifically larviculture, of J. edwardsii, particularly in the earlier stages. The use of off-the-shelf products for enrichment of Artemia may be better suited to later-stage phyllosomas. Feeding trials of phyllosomas and early juveniles using Artemia fed or enriched with these or similar diets are needed to ascertain the suitability of the diets and to confirm whether the survival and growth rates of rock-lobster larvae can be improved.

\section{Acknowledgements}

C. F. Phleger gratefully acknowledges a CSIRO McMaster Fellowship and M. M. Nelson the University of Tasmania Thomas Crawford Memorial Scholarship. This work was supported in part by the Fisheries Research and Development Corporation. Danny Holdsworth managed the CSIRO GC-MS facility. Members of the CSIRO Marine Products team, in particular PattiVirtue and Mark Rayner, and Denise Schilling are thanked for their support during manuscript preparation. We thank Russell Bradford for provision of ethanolpreserved phyllosomas from Tasmanian waters and Phil James for collection of phyllosomas from New Zealand. Michael Bruce provided valuable comments on the draft manuscript.

\section{References}

Benson, A. A., and Lee, R. F. (1975). The role of wax in oceanic food chains. Scientific American 232, 77-86.

Bligh, E. G., and Dyer, W. J. (1959). A rapid method of total lipid extraction and purification. Canadian Journal of Biochemistry and Physiology 37, 911-17.

Booth, J. D. (1994). Jasus edwardsii larval recruitment off the east coast of New Zealand. Crustaceana (Leiden) 66, 295-317. 
Breen, P. A., and Kendrick, T. H. (1997). A fisheries management success story: the Gisborne, New Zealand, fishery for red rock lobsters (Jasus edwardsii). Marine and Freshwater Research 48, 1103-10.

Bruce, R., Bradford, R., Griffin, D., Gardner, C., and Young, J. (1996). 'A Synthesis of Existing Data on Larval Rock Lobster Distribution in Southern Australia'. Report to Fisheries Research and Development Corporation, CSIRO Marine Laboratories, Hobart.

Castell, J. D., and Covey, J. F. (1976). Dietary lipid requirements of adult lobsters, Homarus americanus (M. E). Journal of Nutrition 106, 1159-65.

Chapelle, S. (1986). Aspects of phospholipid metabolism in crustaceans as related to changes in environmental temperatures and salinities. Comparative Biochemistry and Physiology 84, 423-39.

D’Abramo, L. R., Bordner, C. E., Conklin, D. E., and Baum, N. A. (1984). Sterol requirement of juvenile lobsters, Homarus sp. Aquaculture 42, 13-25.

Evjemo, J. O., Coutteau, P., Olsen, Y., and Sorgeloos, P. (1997). The stability of docosahexaenoic acid in two Artemia species following enrichment and subsequent starvation. Aquaculture 155, 135-48.

Hagen, W., Van Vleet, E. S., and Kattner, G. (1996). Seasonal lipid storage as overwintering strategy of Antarctic krill. Marine Ecology Progress Series 134, 85-89.

Harel, M., Ozkizilcik, S., Lund E., Behrens, P., and Place, A. R. (1999). Enhanced absorption of docosahexaenoic acid (DHA, 22:6n-3) in Artemia nauplii using a dietary combination of DHA-rich phospholipids and DHA-sodium salts. Comparative Biochemistry and Physiology B 124, 169-76.

Illingworth, J., Tong, L. J., Moss, G. A., and Pickering, T. D. (1997). Upwelling tank for culturing rock lobster (Jasus edwardsii) phyllosomas. Marine and Freshwater Research 48, 911-14.

Jeffs, A. G., Willmott, M. E., and Wells, R. M. G. (1999). The use of energy stores in the puerulus of the spiny lobster Jasus edwardsii across the continental shelf of New Zealand. Comparative Biochemistry and Physiology A 123, 351-57.

Jeffs, A. G., Nichols, P. D., and Bruce, M. P. (submitted). Lipid reserves used by the puerulus of the spiny lobster Jasus edwardsii in crossing the continental shelf of New Zealand. Comparative Biochemistry and Physiology.

Kanazawa, A., and Koshio, S. (1994). Lipid nutrition of the spiny lobster Panulirus japonicus (Decapoda, Palinuridae): a review. Crustaceana 67, 226-32.

Kanazawa, A., Teshima, S., and Ono, K. (1979). Relationship between essential fatty acid requirements of aquatic animals and the capacity for bioconversion of linolenic acid to highly unsaturated fatty acids. Comparative Biochemistry Physiology B 63, 295-98.

Kittaka, J. (1990). Ecology and behaviour of puerulus of spiny lobster. La Mer 28, 255-59.

Kittaka, J. (1994a). Larval rearing. In 'Spiny Lobster Management'. (Eds B. F. Phillips, J. S. Cobb, and J. Kittaka.) pp. 402-23. (Fishing News Books: Oxford.)

Kittaka, J. (1994b). Culture of phyllosomas of spiny lobster and its application to studies of larval recruitment and aquaculture. Crustaceana 66, 258-70.

Leger, P., Bengston, D. A., Sorgeloos, P., Simpson, K. L., and Beck, A. D. (1987). The nutritional value of Artemia: a review. In 'Artemia Research and Its Applications' Vol. 3. (Eds P. Sorgeloos, D. A. Bengston, W. Decleir, and E. Jasper.) pp. 556. (Universa Press, Wetteren, Belgium.) 
Lemmens, J. W. T. J. (1994). Biochemical evidence for absence of feeding in puerulus larvae of the western rock lobster Panulirus cygnus (Decapoda: Palinuridae). Marine Biology $118,383-91$.

Lesser, J. H. R. (1978). Phyllosoma larvae of Jasus edwardsii (Hutton) (Crustacea: Decapoda: Palinuridae) and their distribution off the east coast of the North Island, New Zealand. New Zealand Journal of Marine and Freshwater Research 12, 357-70.

Lewis, T., Nichols, P. D., Hart, P. R., Nichols, D. S., and McMeekin, T. A. (1998). Enrichment of rotifers Brachionus plicatilus with eicosapentaenoic acid and docosahexaenoic acid produced by bacteria. Journal of World Aquaculture Society 29, 313-18.

McEvoy, L. A., and Sargent, J. R. (1998). Problems and techniques in live prey enrichment. Proceedings of the Live Feeds Session, Aquaculture Canada 98, 12-16.

Nelson, M. M., Phleger, C. F., Mooney, B. D., and Nichols, P. D. (2000). Lipids of gelatinous Antarctic zooplankton: Cnidaria and Ctenophora. Lipids 35, 1-9.

Nichols, P. D., Holdsworth, D. G., Volkman, J. K., Daintith, M., and Allanson, S. (1989). High incorporation of essential fatty acids by the rotifer Brachionus plicatilis fed on the Prymnesiophyte alga Parlova lutheri. Australian Journal of Marine and Freshwater Research 40, 645-55.

Nichols, P. D., Bakes, M. J., and Elliott, N. G. (1998a) Docosahexanoic acid-rich liver oils from temperate Australian sharks. Marine and Freshwater Research 49, 763-67.

Nichols, P. D., Virtue, P., Mooney, B. D., Elliott, N. G., and Yearsley, G. K. (1998b). Seafood the good food. The oil (fat) content and composition of Australian commercial fishes, shellfishes and crustaceans. CSIRO Marine Research. FRDC Project 95/122.

Olsen, Y. (1998). Lipids and essential fatty acids in aquatic food webs: what can freshwater ecologists learn from mariculture? In 'Lipids in Freshwater Ecosystems'. (Eds M. T. Arts and B. C. Wainman.) pp. 161-202. (Springer: NewYork.)

Pearce, A. (1997). The nutritional condition of newly settled Jasus edwardsii (Hutton 1875) (Palinuridae). BSc. (Hons) Thesis, Department of Zoology, University of Tasmania, Australia, 104 pp.

Phillips, B. F., and Sastry, A. N. (1980). Larval ecology. In 'The Biology and Management of Lobsters'. (Eds J. S. Cobb and B. F. Phillips.) pp. 11-57. (Academic Press: New York.)

Phleger, C. F., Nelson, M. M., Mooney, B. D., and Nichols, P. D. (2000). Lipids of Antarctic salps and their commensal hyperid amphipods. Polar Biology 23, 329-37.

Pond, D. W., and Sargent, J. R. (1998). Lipid composition of the pelagic tunicate Dolioletta gegenbauri (Tunicata, Thaliacea). Journal of Plankton Research 20, 169-74.

Punt, A. E., and Kennedy, R. B. (1997). Population modeling of Tasmanian rock lobster, Jasus edwardsii, resources. Marine and Freshwater Research 48, 967-80.

Rees, J. F., Cure, K., Piyatiratitivorakul, S., Sorgeloos, P., and Menasveta, P. (1994). Highly unsaturated fatty acid requirements of Penaeus monodon postlarvae: an experimental approach based on Artemia enrichment. Aquaculture 122, 193-207.

Smith, G. G. (1999). Effects of temperature during embryonic development on the characteristics of Jasus edwardsii phyllosomas. BSc. (Hons) Thesis, School of Aquaculture, University of Tasmania, Australia, $58 \mathrm{pp}$.

Takahashi, Y., Nishida, S., and Kittaka, J. (1994). Histological characteristics of fat bodies in the puerulus of the rock lobster Jasus edwardsii (Hutton 1857) (Decapoda, Palinuridae). Crustaceana 66, 318-25. 
Teshima, S., and Kanazawa, A. (1971). Biosynthesis of sterols in the lobster, Penaeus japonicus, and the crab, Portunus trituberculatus. Comparative Biochemistry and Physiology B 38, 597-602.

Tong, L. J., Moss, G. A., Paewai, M. M. and Pickering, T. D. (1997). Effect of brine-shrimp numbers on growth and survival of early-stage phyllosomas larvae of rock lobster Jasus edwardsii. Marine and Freshwater Research 48, 935-40.

Van Ballaer, E., Amat, F., Hontoria, F., Leger, P., and Sorgeloos, P. (1985). Preliminary results on the nutritional evaluation of omega-3 PUFA enriched Artemia nauplii for larvae of the sea bass, Dicentrarchus labrax. Aquaculture 49, 223-29.

Virtue, P., Nicol, S., and Nichols, P. D. (1993). Changes in the digestive gland of Euphausia superba during short-term starvation: lipid class, fatty acid and sterol content and composition. Marine Biology 117, 441-48.

Volkman, J. K., and Nichols, P. D. (1991). Applications of thin layer chromatography-flame ionisation detection to the analysis of lipids and pollutants in marine and environmental samples. Journal of Planar Chromatography 4, 19-26.

Volkman, J. K., Jeffery, S. W., Nichols, P. D., Rogers, G. I., and Garland, C. D. (1989). Fatty acid and lipid composition of 10 species of microalgae used in mariculture. Journal of Experimental Marine Biology and Ecology 128, 219-40.

Watanabe, T., Ohta, M., Kitajima, C., and Fujita, S. (1982). Improvement of dietary value of brine shrimp Artemia salina for fish larvae by feeding them on omega-3 highly unsaturated fatty acids. Bulletin of Japanese Society of Scientific Fisheries 48, 1775-82.

Zandee, D. I. (1967). Absence of cholesterol synthesis as contrasted with the presence of fatty acid synthesis in some arthropods. Comparative Biochemistry and Physiology B 20, 811-22. 


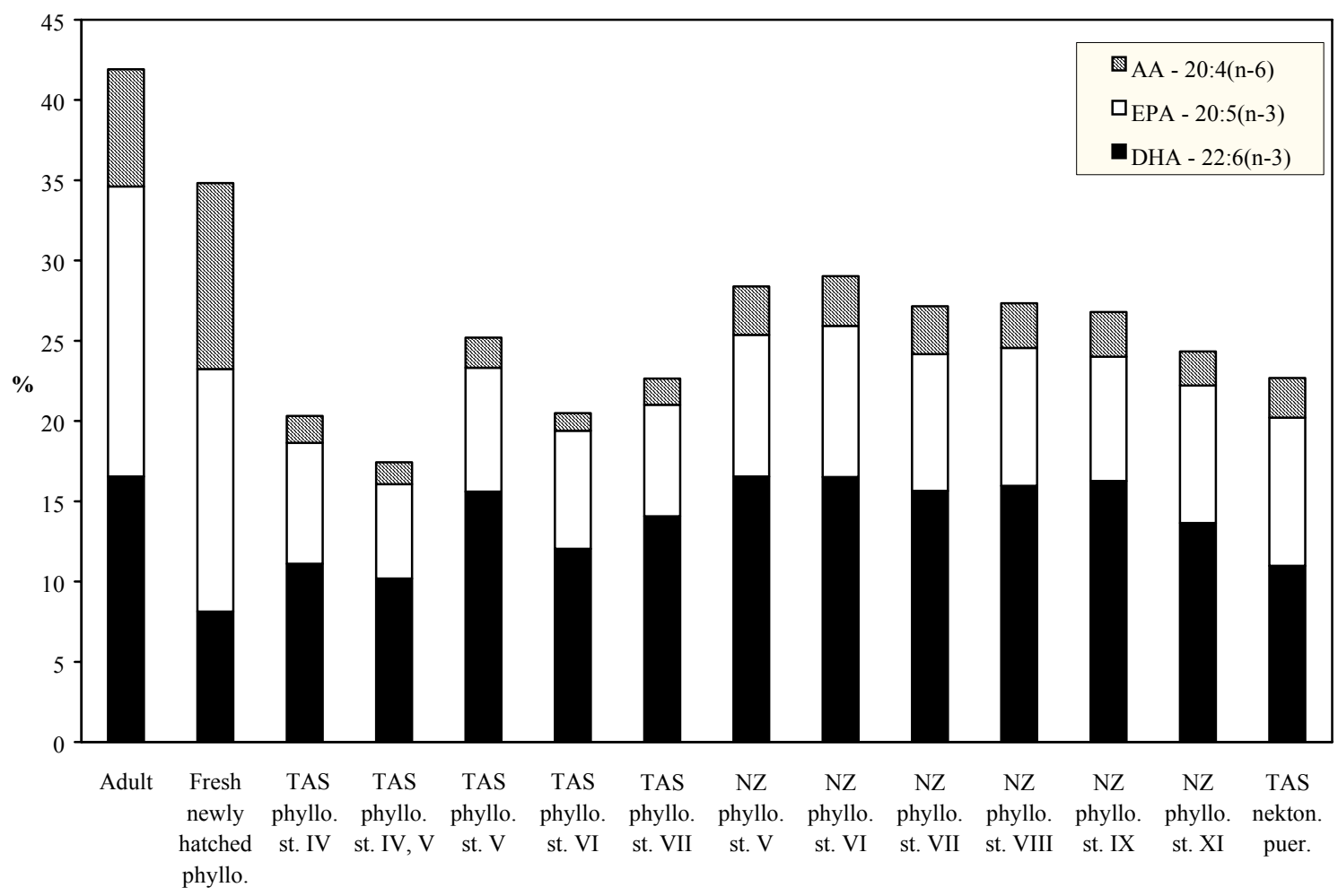

Fig. 1. Percent composition of arachidonic acid (AA), eicosapentaenoic acid (EPA) and docosahexaenoic acid (DHA) in southern rock lobster Jasus edwardsii . Phyllo = phyllosoma; puer. = pueruli.

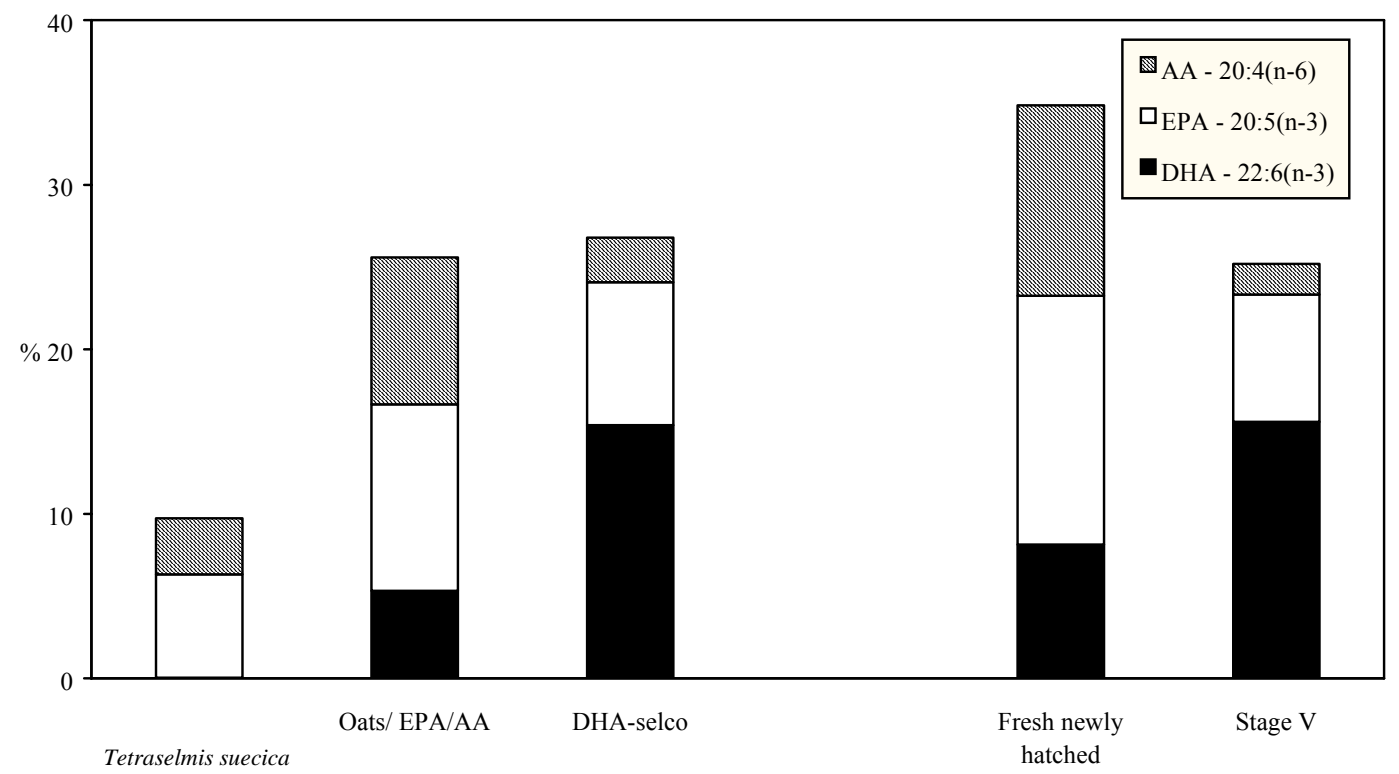

5 day Artemia

Phyllosoma

Fig. 2. Percent composition of arachidonic acid (AA), eicosapentaenoic acid (EPA) and docosahexaenoic acid (DHA) in Artemia and phyllosoma of southern rock lobster Jasus edwardsii. 
Table 1. Percentage lipid class composition of southern rock lobster, Jasus edwardsii.

\begin{tabular}{|c|c|c|c|c|c|c|c|c|}
\hline & $n$ & Wax esters & Triacyglycerols & $\begin{array}{l}\text { Free fatty } \\
\text { acids }\end{array}$ & Diacyglycerols & Sterols & Polar lipids & $\begin{array}{l}\text { Lipid as } \mathrm{mg} \mathrm{g}^{-} \\
\text {dry mass }\end{array}$ \\
\hline Adult $^{1}$ & 3 & - & - & $0.2 \pm 0.3$ & - & $8.8 \pm 0.6$ & $91.1 \pm 0.8$ & $31.0 \pm 4.02$ \\
\hline \multicolumn{9}{|c|}{ Newly hatched phyllosomas-variation with storage treatment ${ }^{3}$} \\
\hline Fresh & 3 & $0.7 \pm 0.1$ & $0.2 \pm 0.0$ & - & $0.5 \pm 0.1$ & $6.6 \pm 0.9$ & $92.0 \pm 1.1$ & $54.5 \pm 9.0^{2}$ \\
\hline Frozen & 2 & $0.8 \pm 0.1$ & $0.3 \pm 0.1$ & $0.5 \pm 0.4$ & $0.5 \pm 0.1$ & $6.4 \pm 0.0$ & $91.5 \pm 0.5$ & $56.5 \pm 2.5^{2}$ \\
\hline Lyophilized & 2 & $0.7 \pm 0.2$ & $0.2 \pm 0.1$ & $0.8 \pm 0.1$ & $0.4 \pm 0.0$ & $6.2 \pm 0.5$ & $91.6 \pm 0.9$ & $45.0 \pm 4.0^{2}$ \\
\hline Ethanol & 2 & $1.0 \pm 0.0$ & $0.5 \pm 0.0$ & $2.0 \pm 0.5$ & $0.7 \pm 0.1$ & $6.4 \pm 0.2$ & $89.3 \pm 0.7$ & $49.0 \pm 1.5^{2}$ \\
\hline Formalin & 2 & $0.6 \pm 0.0$ & $0.3 \pm 0.1$ & $3.0 \pm 0.0$ & $0.2 \pm 0.0$ & $8.2 \pm 0.7$ & $87.6 \pm 0.8$ & $43.5 \pm 1.5^{2}$ \\
\hline \multicolumn{9}{|c|}{ Phyllosomas-west coast Tasmania } \\
\hline Stage IV & $9^{4}$ & - & - & - & 5.5 & 12.0 & 82.5 & 107.4 \\
\hline Stage IV, V & 2 & - & - & - & 4.0 & 4.1 & 91.9 & 235.3 \\
\hline Stage V & 1 & - & - & - & 7.1 & 1.0 & 91.9 & 347.3 \\
\hline Stage VI & 1 & - & - & - & 2.0 & 2.0 & 95.9 & 94.6 \\
\hline Stage VII & 2 & - & - & - & 2.1 & 5.5 & 92.4 & 319.1 \\
\hline \multicolumn{9}{|c|}{ Phyllosomas-New Zealand } \\
\hline Stage V & 5 & trace & 0.2 & 0.1 & 6.2 & 1.5 & 91.9 & $206.6^{2}$ \\
\hline Stage VI & 5 & - & 0.3 & 0.1 & 4.5 & 0.8 & 94.3 & $242.1^{2}$ \\
\hline Stage VII & 5 & - & 0.1 & 0.1 & 6.9 & 1.4 & 91.4 & $194.4^{2}$ \\
\hline Stage VIII & 5 & - & 0.1 & 0.1 & 5.2 & 1.2 & 93.4 & $185.7^{2}$ \\
\hline Stage IX & 1 & - & 0.1 & 0.3 & 6.1 & 1.4 & 92.1 & $279.4^{2}$ \\
\hline Stage XI & 1 & - & 0.1 & 0.1 & 5.2 & 1.9 & 92.7 & $344.0^{2}$ \\
\hline \multicolumn{9}{|c|}{ Pueruli-west coast Tasmania } \\
\hline Nektonic & 3 & - & - & - & $4.1 \pm 1.2$ & $1.4 \pm 1.0$ & $94.5 \pm 1.9$ & $34.8 \pm 17.9$ \\
\hline
\end{tabular}

Presented as mean $\pm \mathrm{sd}$; - , below detection; trace $<0.05 \%$.

${ }^{1}$ From Nichols et al. (1998).

${ }^{2}$ Calculated from wet mass assuming $80 \%$ water.

${ }^{3}$ Storage treatments - all 90 days, fresh samples extracted at time of harvest, 300-400 newly hatched phyllosomas per sample.

${ }^{4}$ Pooled individuals. 
Table 2. Percentage fatty acid composition of southern rock lobster Jasus edwardsii.

\begin{tabular}{|c|c|c|c|c|c|c|c|c|c|c|c|c|c|c|c|c|c|c|}
\hline & \multirow[t]{2}{*}{ Adult } & \multicolumn{5}{|c|}{ Newly hatched phyllosoma - variation with storage } & \multicolumn{5}{|c|}{ Phyllosoma - TAS } & \multicolumn{6}{|c|}{ Phyllosoma - NZ } & \multirow{2}{*}{$\begin{array}{c}\text { Pueruli - TAS } \\
\text { Nektonic } \\
\end{array}$} \\
\hline & & Fresh & Frozen & Lyophilized & Ethanol & Formalin & IV & IV, V & $\mathrm{V}$ & VI & VII & $\mathrm{V}$ & $\mathrm{VI}$ & VII & VIII & IX & $\mathrm{XI}$ & \\
\hline i14:0 & $2.1 \pm 1.9$ & - & - & - & - & - & - & & - & 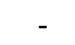 & - & - & - & - & - & - & - & 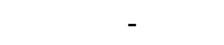 \\
\hline 14:0 & $1.6 \pm 0.1$ & $0.8 \pm 0.0$ & $0.8 \pm 0.0$ & $0.8 \pm 0.0$ & $0.9 \pm 0.0$ & $1.1 \pm 0.0$ & 4.4 & 2.7 & 3.6 & 3.9 & 3.9 & 3.7 & 3.6 & 3.5 & 3.7 & 3.7 & 3.2 & $2.3 \pm 0.5$ \\
\hline $15: 0$ & $1.1 \pm 0.1$ & $0.7 \pm 0.0$ & $0.7 \pm 0.0$ & $0.8 \pm 0.0$ & $0.7 \pm 0.0$ & $1.0 \pm 0.0$ & 1.1 & 1.2 & 1.6 & 1.2 & 1.8 & 1.3 & 1.4 & 1.4 & 1.4 & 1.5 & 1.0 & $0.7 \pm 0.2$ \\
\hline $16: 1(\mathrm{n}-9) \mathrm{c}$ & - & $0.1 \pm 0.1$ & $0.1 \pm 0.0$ & $0.1 \pm 0.0$ & $0.1 \pm 0.0$ & $0.1 \pm 0.0$ & 2.6 & 2.4 & 0.0 & 2.2 & 1.9 & $\operatorname{tr}$ & $\operatorname{tr}$ & $\operatorname{tr}$ & $\operatorname{tr}$ & $\operatorname{tr}$ & $\operatorname{tr}$ & $0.3 \pm 0.2$ \\
\hline $16: 1(\mathrm{n}-7) \mathrm{c}$ & $4.6 \pm 0.3$ & $3.3 \pm 0.1$ & $3.6 \pm 0.2$ & $3.7 \pm 0.0$ & $3.4 \pm 0.0$ & $4.4 \pm 0.1$ & 4.7 & 2.6 & 6.5 & 3.8 & 4.5 & 6.0 & 5.9 & 6.2 & 6.3 & 6.9 & 5.9 & $5.0 \pm 0.6$ \\
\hline $16: 1(n-7) t / 16: 2$ & - & $0.3 \pm 0.0$ & $0.2 \pm 0.1$ & $0.1 \pm 0.0$ & $0.3 \pm 0.0$ & $0.5 \pm 0.0$ & 0.6 & 0.4 & 1.5 & 0.3 & 1.5 & 1.1 & 1.2 & 1.3 & 1.1 & 1.2 & 0.8 & $0.7 \pm 0.3$ \\
\hline $16: 0$ & $13.2 \pm 0.7$ & $14.5 \pm 0.5$ & $14.6 \pm 0.1$ & $14.5 \pm 0.1$ & $14.2 \pm 0.1$ & $18.2 \pm 0.2$ & 14.1 & 15.5 & 21.1 & 21.7 & 18.6 & 19.7 & 19.7 & 20.2 & 20.2 & 20.5 & 19.7 & $15.6 \pm 2.6$ \\
\hline i17:0 & $0.5 \pm 0.1$ & $0.7 \pm 0.0$ & $0.8 \pm 0.0$ & $0.8 \pm 0.0$ & $0.8 \pm 0.0$ & $1.0 \pm 0.0$ & 0.1 & 0.5 & 0.2 & 0.2 & 0.2 & 0.3 & 0.2 & 0.2 & 0.2 & 0.2 & 0.2 & $0.2 \pm 0.1$ \\
\hline a17:0 & - & $0.6 \pm 0.0$ & $0.6 \pm 0.0$ & $0.6 \pm 0.0$ & $0.6 \pm 0.0$ & $0.7 \pm 0.0$ & - & - & - & - & - & 0.3 & 0.3 & 0.3 & 0.3 & 0.3 & 0.2 & - \\
\hline $17: 1(\mathrm{n}-8) \mathrm{c}$ & $1.6 \pm 0.2$ & $0.6 \pm 0.0$ & $0.6 \pm 0.0$ & $0.7 \pm 0.0$ & $0.6 \pm 0.0$ & $0.8 \pm 0.0$ & 1.3 & 1.5 & 0.9 & 0.9 & 1.1 & 0.5 & 0.6 & 0.6 & 0.6 & 0.6 & 0.5 & $0.8 \pm 0.1$ \\
\hline $17: 0$ & $1.6 \pm 0.1$ & $1.5 \pm 0.0$ & $1.6 \pm 0.0$ & $1.5 \pm 0.0$ & $1.5 \pm 0.0$ & $1.8 \pm 0.0$ & 0.7 & 1.0 & 0.7 & 0.7 & 1.1 & 1.0 & 1.0 & 1.1 & 1.0 & 1.0 & 0.8 & $0.8 \pm 0.1$ \\
\hline $18: 4(\mathrm{n}-3) \mathrm{c}$ & - & - & - & - & - & - & 0.6 & 0.7 & 1.0 & 0.6 & 0.9 & 1.4 & 1.3 & 1.2 & 1.3 & 1.2 & 0.9 & - \\
\hline $18: 2(\mathrm{n}-6) / \mathrm{a} 18: 0$ & $1.7 \pm 0.2$ & $1.4 \pm 0.1$ & $1.3 \pm 0.0$ & $1.3 \pm 0.0$ & $1.3 \pm 0.0$ & $1.1 \pm 0.0$ & 3.4 & 6.5 & 1.1 & 2.0 & 1.6 & 1.1 & 1.2 & 1.1 & 1.2 & 1.2 & 0.9 & $1.7 \pm 0.7$ \\
\hline $18: 1(\mathrm{n}-9) \mathrm{c}$ & $12.2 \pm 0.4$ & $12.6 \pm 0.2$ & $13.3 \pm 0.1$ & $12.9 \pm 0.2$ & $12.7 \pm 0.1$ & $15.9 \pm 0.2$ & 30.6 & 26.7 & 19.1 & 24.6 & 21.0 & 16.6 & 16.1 & 17.1 & 17.2 & 17.1 & 20.0 & $26.5 \pm 7.7$ \\
\hline $18: 1(\mathrm{n}-7) \mathrm{c}$ & $2.8 \pm 0.5$ & $5.1 \pm 0.2$ & $5.2 \pm 0.1$ & $5.2 \pm 0.1$ & $5.3 \pm 0.1$ & $6.5 \pm 0.0$ & 4.3 & 4.7 & 2.8 & 1.8 & 3.2 & 2.3 & 2.3 & 2.3 & 2.3 & 2.2 & 2.8 & $4.2 \pm 0.8$ \\
\hline $18: 0$ & $6.6 \pm 0.3$ & $6.9 \pm 0.2$ & $6.9 \pm 0.2$ & $7.1 \pm 0.1$ & $7.0 \pm 0.0$ & $8.5 \pm 0.1$ & 6.2 & 8.5 & 7.7 & 10.5 & 7.6 & 7.8 & 8.1 & 7.9 & 8.0 & 8.0 & 8.4 & $9.1 \pm 0.3$ \\
\hline 20:4(n-6) - AA & $7.3 \pm 0.7$ & $11.6 \pm 0.3$ & $11.7 \pm 0.2$ & $11.9 \pm 0.2$ & $11.6 \pm 0.1$ & $8.4 \pm 0.1$ & 1.7 & 1.4 & 1.9 & 1.1 & 1.6 & 3.0 & 3.1 & 3.0 & 2.8 & 2.8 & 2.1 & $2.4 \pm 0.2$ \\
\hline 20:5(n-3) - EPA & $18.1 \pm 1.1$ & $15.1 \pm 0.4$ & $14.8 \pm 0.0$ & $14.9 \pm 0.2$ & $15.3 \pm 0.3$ & $10.3 \pm 0.1$ & 7.5 & 5.9 & 7.7 & 7.4 & 6.9 & 8.8 & 9.4 & 8.5 & 8.6 & 7.7 & 8.6 & $9.2 \pm 0.8$ \\
\hline $20: 2(n-6)$ & $0.7 \pm 0.0$ & $2.1 \pm 0.1$ & $2.2 \pm 0.0$ & $2.1 \pm 0.1$ & $2.1 \pm 0.0$ & $2.4 \pm 0.1$ & 0.2 & 0.4 & 0.5 & 0.3 & 0.6 & 0.5 & 0.5 & 0.4 & 0.5 & 0.5 & 0.5 & $0.5 \pm 0.1$ \\
\hline $20: 1(n-11) c$ & - & $0.6 \pm 0.1$ & $0.6 \pm 0.0$ & $0.6 \pm 0.0$ & $0.6 \pm 0.0$ & $0.7 \pm 0.0$ & 1.1 & 1.2 & 2.3 & 1.3 & 1.3 & 2.0 & 1.9 & 2.1 & 1.9 & 1.8 & 4.4 & $3.3 \pm 1.1$ \\
\hline $20: 1(n-9) c$ & $2.8 \pm 0.2$ & $2.0 \pm 0.3$ & $1.8 \pm 0.1$ & $1.8 \pm 0.0$ & $1.9 \pm 0.0$ & $2.3 \pm 0.1$ & 0.1 & 0.3 & 0.5 & 0.2 & 0.4 & - & - & - & - & - & - & $0.6 \pm 0.3$ \\
\hline $20: 0$ & $1.0 \pm 0.1$ & $0.6 \pm 0.0$ & $0.6 \pm 0.1$ & $0.6 \pm 0.0$ & $0.5 \pm 0.0$ & $0.7 \pm 0.1$ & 0.6 & 0.5 & 0.4 & 0.7 & 0.7 & 0.5 & 0.5 & 0.5 & 0.5 & 0.5 & 0.4 & $0.4 \pm 0.1$ \\
\hline 22:6(n-3) - DHA & $16.6 \pm 1.3$ & $8.1 \pm 0.1$ & $7.6 \pm 0.1$ & $7.8 \pm 0.0$ & $7.9 \pm 0.1$ & $4.7 \pm 0.1$ & 11.1 & 10.2 & 15.6 & 12.0 & 14.1 & 16.6 & 16.5 & 15.7 & 16.0 & 16.3 & 13.6 & $11.0 \pm 2.6$ \\
\hline $22: 4(n-6)$ & $0.1 \pm 0.2$ & $1.5 \pm 0.0$ & $1.5 \pm 0.1$ & $1.5 \pm 0.0$ & $1.6 \pm 0.0$ & $1.1 \pm 0.0$ & 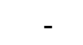 & $\operatorname{tr}$ & 0.1 & - & 1.8 & 0.1 & 0.1 & 0.1 & 0.1 & 0.1 & 0.1 & $0.1 \pm 0.1$ \\
\hline 22:5(n-3) - DPA & $0.7 \pm 0.1$ & $2.0 \pm 0.0$ & $1.9 \pm 0.1$ & $1.9 \pm 0.0$ & $2.0 \pm 0.0$ & $1.2 \pm 0.0$ & 0.2 & 0.3 & 0.6 & - & 0.2 & 0.6 & 0.5 & 0.5 & 0.5 & 0.5 & 0.4 & $0.4 \pm 0.2$ \\
\hline $22: 1(\mathrm{n}-11)$ & $0.6 \pm 0.1$ & $0.2 \pm 0.1$ & $0.2 \pm 0.0$ & $0.2 \pm 0.0$ & $0.2 \pm 0.0$ & $0.2 \pm 0.0$ & - & - & - & - & 0.7 & $\operatorname{tr}$ & $\operatorname{tr}$ & $\operatorname{tr}$ & $\operatorname{tr}$ & $\operatorname{tr}$ & 0.5 & $0.5 \pm 0.3$ \\
\hline $22: 1(\mathrm{n}-9)$ & - & $0.2 \pm 0.1$ & $0.2 \pm 0.0$ & $0.2 \pm 0.0$ & $0.2 \pm 0.0$ & $0.2 \pm 0.1$ & 1.0 & 3.1 & 0.5 & 0.8 & 1.2 & 0.2 & 0.1 & 0.2 & 0.2 & 0.1 & 0.5 & $1.0 \pm 0.4$ \\
\hline Other & 2.7 & 6.9 & 6.7 & 6.4 & 6.6 & 6.0 & 2.0 & 1.8 & 2.3 & 1.7 & 0.8 & 4.6 & 4.5 & 4.8 & 4.2 & 3.9 & 3.7 & 2.9 \\
\hline Sum SFA & $28.1 \pm 1.3$ & $28.2 \pm 0.6$ & $28.6 \pm 0.2$ & $28.8 \pm 0.2$ & $28.1 \pm 0.1$ & $35.1 \pm 0.5$ & 29.4 & 32.3 & 37.3 & 40.6 & 35.7 & 31.6 & 31.8 & 32.2 & 32.2 & 32.8 & 31.3 & $30.9 \pm 3.9$ \\
\hline Sum MUFA & $25.4 \pm 0.8$ & $27.6 \pm 1.0$ & $27.5 \pm 0.1$ & $27.2 \pm 0.0$ & $27.1 \pm 0.0$ & $33.7 \pm 0.2$ & 46.8 & 43.1 & 34.1 & 36.3 & 37.4 & 30.1 & 29.4 & 30.8 & 30.8 & 31.2 & 36.7 & $43.3 \pm 6.5$ \\
\hline Sum PUFA & $46.5 \pm 1.0$ & $43.5 \pm 0.6$ & $42.6 \pm 0.2$ & $43.1 \pm 0.1$ & $43.4 \pm 0.2$ & $30.7 \pm 0.2$ & 25.0 & 26.2 & 29.5 & 24.0 & 28.1 & 33.5 & 34.1 & 32.2 & 32.3 & 31.8 & 28.6 & $26.5 \pm 2.8$ \\
\hline Sum (n-3) & $36.1 \pm 1.8$ & $25.6 \pm 0.6$ & $24.7 \pm 0.1$ & $25.0 \pm 0.1$ & $25.7 \pm 0.3$ & $16.6 \pm 0.2$ & 19.5 & 17.3 & 25.3 & 20.0 & 22.3 & 27.8 & 28.1 & 26.4 & 26.9 & 26.1 & 24.3 & $21.3 \pm 3.4$ \\
\hline Sum (n-6) & $10.3 \pm 0.9$ & $17.2 \pm 0.4$ & $17.4 \pm 0.1$ & $17.5 \pm 0.2$ & $17.2 \pm 0.1$ & $13.7 \pm 0.1$ & 5.5 & 8.7 & 4.1 & 4.0 & 5.7 & 5.5 & 5.8 & 5.6 & 5.2 & 5.6 & 4.2 & $5.1 \pm 0.7$ \\
\hline Ratio (n-3)/(n-6) & 3.50 & 1.49 & 1.42 & 1.43 & 1.49 & 1.22 & 3.53 & 1.98 & 6.10 & 5.02 & 3.88 & 5.04 & 4.86 & 4.67 & 5.18 & 4.68 & 5.81 & 4.14 \\
\hline Ratio EPA/AA & 2.47 & 1.31 & 1.26 & 1.26 & 1.33 & 1.23 & 4.53 & 4.31 & 4.13 & 6.73 & 4.27 & 2.91 & 3.04 & 2.85 & 3.09 & 2.77 & 4.05 & 3.77 \\
\hline Ratio DHA/EPA & 0.92 & 0.54 & 0.52 & 0.52 & 0.52 & 0.46 & 1.47 & 1.74 & 2.02 & 1.64 & 2.02 & 1.88 & 1.75 & 1.84 & 1.86 & 2.10 & 1.59 & 1.19 \\
\hline
\end{tabular}

presented as mean $\pm \mathrm{sd}$; (-), below detection; tr, trace $(<0.05 \%)$; AA, arachidonic acid; EPA, eicosapentaenoic acid; DHA, docosahexaenoic acid; DPA, docosapentaenoic acid; details provided in Table 1; Other includes components present at $<1 \%$ : i15:0. a15:0, i16:0, $\mathrm{C}_{16}$ PUFA, 16:1(n-5)c, i18:0, 18:3(n-6)c, 18:3(n-3)c, 18:1(n-7)t, 18:1(n-5), i19:0, 19:1, 20:3(n-6), 20:4(n-3), 20:1(n-7)c, $\mathrm{C}_{21}$ PUFA, 21:0, 22:5(n-6), 22:3(n-3), 22:1(n-7), 22:0, 24:1, 24:0. 
Table 3. Percentage lipid class composition of feed (for feeding to Artemia) and Artemia fed for 5 days. ${ }^{1}$

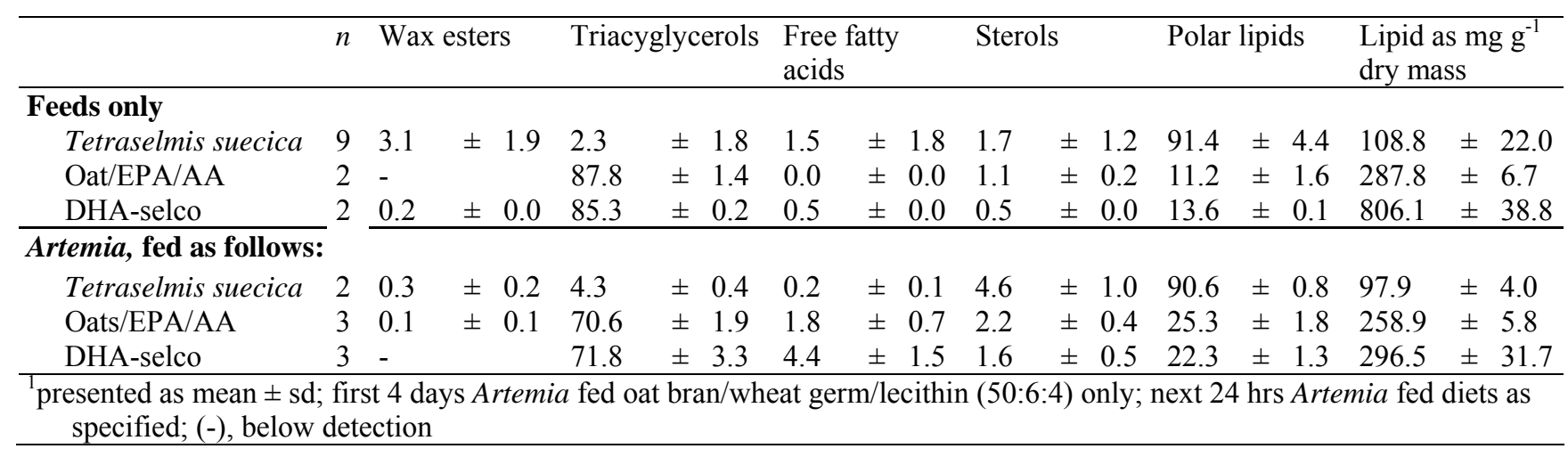


Marine and Freshwater Research 52 (2001) 1475-1486

Author version 19

Table 4. Percentage fatty-acid composition of feed (for feeding to Artemia) and Artemia fed for 5 days ${ }^{1}$.

\begin{tabular}{|c|c|c|c|c|c|c|c|c|c|c|c|c|}
\hline \multirow[b]{3}{*}{ 14:0 } & \multicolumn{6}{|c|}{ Feeds only } & \multicolumn{6}{|c|}{ Artemia, fed as follows: } \\
\hline & \multicolumn{2}{|c|}{$\begin{array}{l}\text { Tetraselmis } \\
\text { suecica }\end{array}$} & \multicolumn{2}{|c|}{ Oats/EPA/AA } & \multicolumn{2}{|c|}{ DHA-selco } & \multicolumn{2}{|c|}{$\begin{array}{l}\text { Tetraselmis } \\
\text { suecica }\end{array}$} & \multicolumn{2}{|c|}{ Oats/EPA/AA } & \multicolumn{2}{|c|}{ DHA-selco } \\
\hline & 0.5 & \pm 0.1 & 5.6 & \pm 0.2 & 3.3 & \pm 0.0 & 0.4 & \pm 0.1 & 2.2 & \pm 0.0 & 1.6 & \pm 0.1 \\
\hline $15: 0$ & - & & 0.4 & \pm 0.1 & 1.0 & \pm 0.0 & - & & 0.1 & \pm 0.0 & 0.3 & \pm 0.1 \\
\hline C16 PUFA & 3.0 & \pm 6.0 & 1.3 & \pm 0.2 & 0.1 & \pm 0.1 & 1.3 & \pm 0.9 & 0.5 & \pm 0.1 & 0.2 & \pm 0.1 \\
\hline $16: 1(n-9) c$ & 1.3 & \pm 0.3 & 0.1 & \pm 0.0 & 0.2 & \pm 0.0 & 0.6 & \pm 0.0 & 0.4 & \pm 0.0 & 0.6 & \pm 0.0 \\
\hline $16: 1(n-7) c$ & 2.0 & \pm 0.6 & 6.6 & \pm 0.6 & 4.2 & \pm 0.2 & 1.5 & \pm 0.1 & 4.8 & \pm 0.1 & 4.1 & \pm 0.1 \\
\hline $16: 0$ & 21.3 & \pm 4.1 & 17.1 & \pm 0.4 & 21.4 & \pm 0.6 & 13.9 & \pm 0.3 & 10.3 & \pm 0.1 & 11.0 & \pm 0.2 \\
\hline a17:0/17:1 & 0.3 & \pm 0.3 & 0.1 & \pm 0.1 & 0.7 & \pm 0.0 & 0.3 & \pm 0.0 & 0.3 & \pm 0.0 & 0.8 & \pm 0.1 \\
\hline $17: 0$ & 0.2 & \pm 0.3 & 0.5 & \pm 0.0 & 1.3 & \pm 0.0 & 0.7 & \pm 0.0 & 0.4 & \pm 0.0 & 0.6 & \pm 0.0 \\
\hline $18: 3(n-6)$ & 1.8 & \pm 0.5 & - & & - & & 1.8 & \pm 0.1 & 0.7 & \pm 0.0 & 0.2 & \pm 0.0 \\
\hline $18: 4(n-3)$ & 9.0 & \pm 1.9 & 1.8 & \pm 0.1 & 0.9 & \pm 0.2 & 4.5 & \pm 0.3 & 2.1 & \pm 0.1 & 1.6 & \pm 0.1 \\
\hline $18: 2(n-6)$ & 19.2 & \pm 5.2 & 10.0 & \pm 0.3 & 5.4 & \pm 0.2 & 17.1 & \pm 0.5 & 16.7 & \pm 0.2 & 13.2 & \pm 0.1 \\
\hline $18: 1(n-9) c / 18: 3(n-3)$ & 22.9 & \pm 4.5 & 14.2 & \pm 0.2 & 18.0 & \pm 3.0 & 23.7 & \pm 0.1 & 22.2 & \pm 0.3 & 24.0 & \pm 0.1 \\
\hline $18: 1(n-7) c$ & 4.1 & \pm 2.2 & 2.8 & \pm 0.0 & 3.0 & \pm 0.2 & 10.3 & \pm 0.5 & 4.1 & \pm 0.1 & 4.7 & \pm 0.2 \\
\hline $18: 0$ & 2.1 & \pm 2.4 & 4.4 & \pm 0.1 & 6.0 & \pm 0.2 & 9.4 & \pm 0.3 & 4.1 & \pm 0.0 & 4.2 & \pm 0.1 \\
\hline $20: 4(n-6)-A A$ & 1.5 & \pm 0.4 & 8.9 & \pm 0.0 & 1.7 & \pm 0.1 & 3.4 & \pm 0.8 & 8.9 & \pm 0.2 & 2.7 & \pm 0.7 \\
\hline $20: 5(n-3)-E P A$ & 5.1 & \pm 0.7 & 11.7 & \pm 0.3 & 5.3 & \pm 0.3 & 6.3 & \pm 0.2 & 11.3 & \pm 0.1 & 8.7 & \pm 0.3 \\
\hline $20: 1(n-11) c$ & 1.3 & \pm 0.5 & 0.8 & \pm 0.0 & 1.0 & \pm 0.0 & 0.9 & \pm 0.0 & 0.6 & \pm 0.0 & 0.7 & \pm 0.0 \\
\hline $22: 5(n-6)$ & - & & 0.3 & \pm 0.1 & 1.6 & \pm 0.1 & 0.1 & \pm 0.1 & 0.2 & \pm 0.0 & 1.1 & \pm 0.1 \\
\hline $22: 6(n-3)-D H A$ & 0.2 & \pm 0.2 & 7.5 & \pm 0.0 & 20.7 & \pm 0.6 & 0.0 & \pm 0.1 & 5.3 & \pm 0.3 & 15.4 & \pm 1.1 \\
\hline $22: 5(n-3)-D P A$ & 0.1 & \pm 0.2 & 1.5 & \pm 0.0 & 0.9 & \pm 0.1 & - & & 1.0 & \pm 0.1 & 0.9 & \pm 0.0 \\
\hline $22: 1$ & 1.8 & \pm 4.8 & 0.5 & \pm 0.0 & 0.3 & \pm 0.0 & - & & 0.3 & \pm 0.0 & 0.2 & \pm 0.0 \\
\hline Other & 2.3 & & 4.0 & & 3.0 & & 3.9 & & 3.4 & & 3.0 & \\
\hline Sum SFA & 25.6 & \pm 2.5 & 28.9 & \pm 0.9 & 34.6 & \pm 1.0 & 26.2 & \pm 0.6 & 18.7 & \pm 0.1 & 19.9 & \pm 0.1 \\
\hline Sum MUFA & 33.6 & \pm 6.5 & 25.8 & \pm 0.4 & 27.9 & \pm 2.5 & 37.5 & \pm 0.3 & 33.2 & \pm 0.5 & 34.9 & \pm 0.2 \\
\hline Sum PUFA & 40.7 & \pm 6.2 & 44.9 & \pm 1.1 & 37.4 & \pm 1.5 & 36.1 & \pm 0.6 & 48.1 & \pm 0.4 & 45.1 & \pm 0.3 \\
\hline Sum (n-3) & 14.7 & \pm 2.0 & 23.0 & \pm 0.4 & 28.1 & \pm 1.1 & 11.3 & \pm 0.5 & 20.3 & \pm 0.5 & 27.0 & \pm 0.8 \\
\hline Sum (n-6) & 23.0 & \pm 5.4 & 20.5 & \pm 0.5 & 9.2 & \pm 0.4 & 23.5 & \pm 0.3 & 27.2 & \pm 0.2 & 17.8 & \pm 0.7 \\
\hline Ratio (n-3)/(n-6) & 0.64 & & 1.12 & & 3.05 & & 0.48 & & 0.75 & & 1.51 & \\
\hline Ratio EPA/AA & 3.32 & & 1.32 & & 3.17 & & 1.85 & & 1.27 & & 3.19 & \\
\hline Ratio DHA/EPA & 0.04 & & 0.64 & & 3.93 & & 0.04 & & 0.47 & & 1.77 & \\
\hline
\end{tabular}

${ }^{1}$ presented as mean $\pm \mathrm{sd}$; details provided in Table 3; first 4 days Artemia fed oat bran/wheat germ/lecithin (50:6:4) only; next 24 hrs Artemia fed diets as specified; (-), below detection; tr, trace $(<0.05 \%)$; AA, arachidonic acid; EPA, eicosapentaenoic acid; DHA, docosahexaenoic acid; DPA, docosapentaenoic acid; other includes components present at $<1 \%$ : i15:0, a15:0, 16:1(n7)t, i17:0, 18:1(n-7)t, 20:4(n-3), 20:3(n-6), 20:2(n-6), 20:1(n-7)c, 20:0, 22:4(n-6), 22:0, 24:1, 24:0. 